\title{
Epidemiological study of drug resistant cholera in and around Miraj, India
}

\author{
Viresh A. Nandimath ${ }^{1}$, Santosh A. Nandimath ${ }^{2}$, Chaithra S. Swamy ${ }^{3}$, Amar R. Ukrande ${ }^{4}$
}

${ }^{1}$ Department of Community Medicine, Dr. Vaishampayan Memorial Government Medical College, Solapur, Maharashtra, India

${ }^{2}$ Department of Maxillofacial Surgery, Vokkaligara Sangha Dental College and Hospital, Bangalore, Karnataka, India ${ }^{3}$ Department of ENT, Bangalore Medical College and Research Institute, Bangalore, Karnataka, India

${ }^{4}$ Department of Microbiology, Government Medical College, Miraj, Maharashtra, India

Received: 02 June 2016

Accepted: 01 July 2016

\section{*Correspondence:}

Dr. Viresh A. Nandimath,

E-mail: viresh_an@yahoo.co.in

Copyright: ( ) the author(s), publisher and licensee Medip Academy. This is an open-access article distributed under the terms of the Creative Commons Attribution Non-Commercial License, which permits unrestricted non-commercial use, distribution, and reproduction in any medium, provided the original work is properly cited.

\section{ABSTRACT}

Background: Cholera is an intestinal infection caused by Vibrio cholerae. The hallmark of the disease is profuse secretory diarrhea. Cholera can be endemic, epidemic, or pandemic. Despite all the major advances in research, the condition still remains a challenge to the modern medical world. Objectives: This study was conducted to observe various epidemiological profile of cholera outbreak and to determine the antibiotic sensitivity pattern of isolates.

Methods: A descriptive study was conducted from 18th January 2010 to 31st July 2010. All confirmed cases of cholera were included in the present study during the study period. Antibiotic sensitivity testing was performed by disc diffusion method.

Results: Total 63 patients of cholera caused by Vibrio cholerae $\mathrm{O} 1$ were admitted in the hospital during the present study; majorities $(60.32 \%)$ of cases were males and cases were more (79.36\%) amongst adults ( $>15$ years). All strains were El Tor. The outbreak started on 18th January 2010, peaked in February and lasted till $24^{\text {th }}$ July 2010. Detection of $V$. cholera $\mathrm{O} 1$ biotype El Tor serotype Ogawa was $81.25 \%$ and rests $(18.75 \%)$ were serotype Inaba. Clinically all cases $(100 \%)$ presented with profuse watery diarrhea, $28.57 \%$ had vomiting, $20.63 \%$ had abdominal cramps while fever was present in $9.53 \%$ of cases. Majority of isolates were sensitive to amikacin and cephalexin but resistant to ampicillin and chloramphenicol.

Conclusions: Provision of safe drinking water, improving sanitation and strengthening of disease surveillance especially in coordination with local health authorities across the border is necessary to avoid recurrences of cholera.

Keywords: Epidemic, El Tor, Inaba, Ogawa, Outbreak, Resistance, Vibrio cholera

\section{INTRODUCTION}

Cholera is an extremely virulent disease. It affects both children and adults and can kill within hours. Among people who develop symptoms, $80 \%$ have mild or moderate symptoms, while around $20 \%$ develop acute watery diarrhoea with severe dehydration. This can lead to death if left untreated. ${ }^{1}$ Cholera, caused by the Gramnegative bacterium Vibrio cholerae, is classically associated with rapidly dehydrating watery diarrhoea. Although more than 200 serogroups of V. cholerae have been identified; only the $\mathrm{O} 1$ and $\mathrm{O} 139$ serogroups are associated with epidemic and pandemic outbreaks. ${ }^{2}$ Vibrio cholerae O1 has two biotypes, classical and El Tor, and two major serotypes, Ogawa and Inaba. Strains of the ogawa serotype express $\mathrm{A}$ and $\mathrm{B}$ antigens and a small amount of $\mathrm{C}$ antigen, whereas the Inaba strains express only the $\mathrm{A}$ and $\mathrm{C}$ antigens. A third serotype, 
which possesses all three antigens, is referred to as Hikojima. The Hikojima serotype is both rare and unstable. Among the three serotypes, the Ogawa serotype is most prevalent. ${ }^{3}$ The main reservoirs of $\mathrm{V}$. cholerae are people and aquatic sources such as brackish water and estuaries, often associated with algal blooms. Recent studies indicate that global warming creates a favourable environment for the bacteria. Cholera transmission is closely linked to inadequate environmental management. Typical at-risk areas include peri-urban slums, where basic infrastructure is not available, where minimum requirements of clean water and sanitation are not met. ${ }^{1}$ The present study was conducted to notice epidemiological profile of cholera outbreak with antibiotic sensitivity of $\mathrm{V}$. cholera. Objective of the study was To determine various epidemiological profile of cholera outbreak. To determine antibiotic sensitivity of $\mathrm{V}$. cholera isolates.

\section{METHODS}

A descriptive study was conducted from $18^{\text {th }}$ January 2010 to $31^{\text {st }}$ July 2010 at Tertiary Care Hospital, Miraj. Predesigned and pretested pro forma semi open-ended questionnaire was used to collect data from cases. All confirmed cases of cholera were included in the present study during the study period.

\section{Case definition utilized for cholera}

The cases of diarrheal diseases fulfilling the WHO Standard case definition of cholera were taken into consideration for this study: A case of cholera should be suspected when: In an area, where the disease is not known to be present, a patient aged 5 years or more develops severe dehydration or dies from acute watery diarrhea; in an area where there is a cholera epidemic, a patient aged 5 years or more develops acute watery diarrhea, with or without vomiting. A case of cholera is confirmed when V. cholerae O1 or O139 is isolated from any patient with diarrhea. ${ }^{4}$

Information regarding age, sex, place of residence, occupation, date of onset and treatment history and laboratory finding were collected.

\section{Environmental investigation}

After reviewing the descriptive epidemiology epidemic occurrence pointed to a contaminated water supply. The investigation team visited the area and collected information regarding water quality, sources of water supply, drainage system and information of mass gathering as well as exposure to mass food consumption.

\section{Laboratory investigation}

Most of the patients had loose rice watery diarrhea. Stool samples were collected from patients admitted in hospital. Stool sample from these patients were collected in a wide mouth, capped sterile container \& enrichment was done with alkaline peptone water at $37^{\circ} \mathrm{C}$ for 6 to 8 hours. Before plating, hanging drop preparation was made to confirm typical darting motility of Vibrio cholerae both directly from the sample and after enrichment in alkaline peptone water. The samples were then plated onto MacConkey agar, blood agar \& Thiosulphate Citrate Bile salt Sucrose (TCBS) agar. The isolates obtained were identified according to recommended standard laboratory methods including polymyxin $(50 \mu \mathrm{g})$ and serotypes were identified by slide agglutination with Vibrio non-differential $\mathrm{O} 1$, monospecific Ogawa and Inaba and Vibrio cholerae O139 antisera. ${ }^{5}$ Antibiotic sensitivity testing of V. cholerae isolates was done on Muller Hinton agar by disc diffusion method of Kirby and Bauer using the following antimicrobial agents: Ampicillin $(10 \mu \mathrm{g})$, tetracycline $(30 \mu \mathrm{g})$, ofloxacin $(5 \mu \mathrm{g})$, chloramphenicol $(30 \mu \mathrm{g})$, gentamycin $(10 \mu \mathrm{g})$, doxycycline $(25 \mu \mathrm{g})$, cephalexin $(10 \mu \mathrm{g})$ and amikacin $(10 \mu \mathrm{g}){ }^{6}$

\section{Ethical consideration}

This study was conducted as an emergency response to the cholera outbreak and was designed to provide information to orient the public health response; hence, ethical approval was not sought prior to the study. It was undertaken as a public health practice rather than as a research. ${ }^{7}$ Privacy, confidentiality and rights of patients were ensured during and after the conduct of the study. Oral informed consent was obtained from the patient after detailed explanation of the existence of an outbreak, the objective of the study and the planed use of the information were explained.

\section{Analysis of data}

Data was entered in Microsoft excel sheet and analysis was done using Statistical software SPSS. Fisher exact test was used for statistical analysis.

\section{RESULTS}

In the present study total 63 patients had cholera, of which $60.32 \%$ were males and $39.68 \%$ were females. Most $(23.81 \%)$ of cases were in 21 to 30 years of age group followed by 11 to 20 years $(20.63 \%), 31$ to 40 years $(19.04 \%), \geq 51$ years $(15.88 \%), 1$ to 10 years $(12.70 \%)$ and least $(7.94 \%)$ in 41 to 50 years of age group. Association between age groups and gender was statistically highly significant (Table 1). Out of 63 cases, $36(57.14 \%)$ cases were from urban locality while 27 $(42.86 \%)$ were from rural area. In the present study cholera cases were seen in the month of February (29 cases), July (16 cases), January (09 cases), June (05 cases) and in April (05 cases) (Figure 1). Vibrio cholera O1 El Tor Ogawa serotype (52) was the most commonly isolated serotype among cholera cases as compared to Vibrio cholera O1 El Tor Inaba serotype (11); Vibrio cholera O1 Inaba serotype was isolated from Sangli city 
most (09) and one each was isolated from Nadives area of Miraj and Athni, Karnataka.

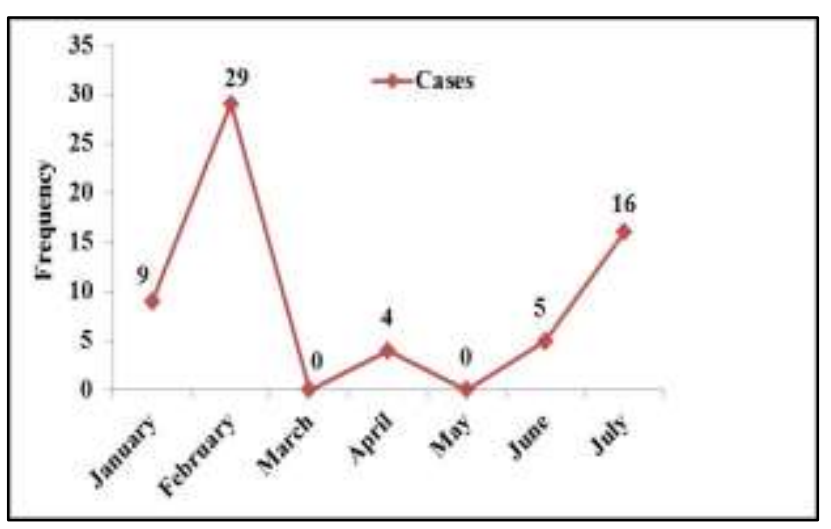

Figure 1: Month wise distribution of cholera.

19 Ogawa serotypes were isolated from Nadives area of Miraj city and 04 were isolated from Nandre area of Miraj City. 17 Ogawa serotypes were isolated from different areas of Sangli city and 10 were isolated Shirol Taluka, Kolhapur while 02 were isolated from Athni Taluka, Karnataka (Table 2), (Figure 2). Loose watery stool was the chief complaint among all cholera cases along with other symptoms like vomiting, abdominal cramps and fever (Table 3). In the present study most $(85 \%)$ of isolates were sensitive to amikacin and gentamycin followed by cephalexin $(80 \%)$, ofloxacin (75\%) and doxycycline (68\%). Maximum isolates were resistance against ampicillin (65\%), chloramphenicol $(58 \%)$ and tetracycline $(40 \%)$ (Table 4$)$.

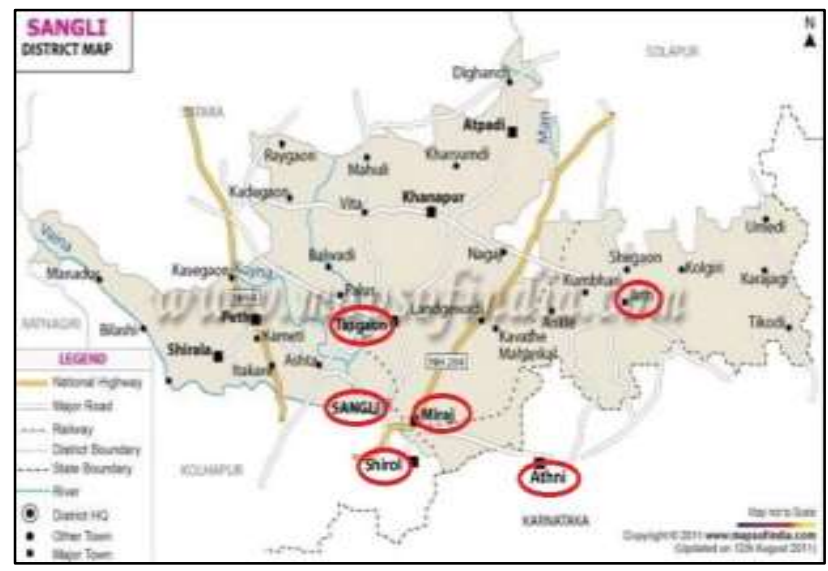

Figure 2: Geographic distribution of cholera.

Table 1: Age and gender wise distribution of cholera patients.

\begin{tabular}{|llll|}
\hline Age group in years & Males $(\%)$ & Females $(\%)$ & Total $(\%)$ \\
\hline $0-10$ & $04(10.53)$ & $04(16)$ & $08(12.70)$ \\
\hline $11-20$ & $10(26.31)$ & $03(12)$ & $13(20.63)$ \\
\hline $21-30$ & $13(34.21)$ & $02(08)$ & $15(23.81)$ \\
\hline $31-40$ & $07(18.42)$ & $05(20)$ & $12(19.04)$ \\
\hline $41-50$ & $01(2.63)$ & $04(16)$ & $05(7.94)$ \\
\hline$\geq 51$ & $03(7.90)$ & $07(28)$ & $10(15.88)$ \\
\hline Total & $38(100)$ & $25(100)$ & $63(100)$ \\
\hline
\end{tabular}

*Fisher Exact Test $=0.0000041 ; \mathrm{p}$ value $<0.01 ;$ Highly Significant.

Table 2: Distribution of different serotypes of Vibrio cholerae.

\begin{tabular}{|c|c|c|c|c|c|}
\hline \multirow[t]{2}{*}{ Month } & \multicolumn{2}{|c|}{ Gender } & \multicolumn{2}{|c|}{ Serotype } & \multirow[t]{2}{*}{ Place of isolation } \\
\hline & Male & Female & Ogawa & Inaba & \\
\hline January & 06 & 03 & 09 & 00 & $\begin{array}{l}\text { Taluka: Shirol, Kolhapur,Nadives, Miraj,Sangli } \\
\text { City. }\end{array}$ \\
\hline February & 17 & 12 & 25 & 04 & $\begin{array}{l}\text { Nadives, Miraj.Taluka: Jat, Sangli.Taluka: } \\
\text { Shirol, Kolhapur. }\end{array}$ \\
\hline April & 03 & 01 & 00 & 04 & Sangli City, Nadives, Miraj. \\
\hline June & 03 & 02 & 04 & 01 & Sangli City,A/P Nandre, Miraj. \\
\hline July & 09 & 07 & 14 & 02 & $\begin{array}{l}\text { Taluka: Tasgaon, Sangli,A/P Nandre, Miraj. } \\
\text { Taluka: Shirol, Kolhapur, Taluka: Athni, } \\
\text { Karnataka. }\end{array}$ \\
\hline Total & 38 & 25 & 52 & 11 & \\
\hline
\end{tabular}

$* \mathrm{~A} / \mathrm{P}=$ At Post. 
Table 3: Age and gender wise distribution of clinical features of cholera patients.

\begin{tabular}{|llllll|}
\hline Gender & Age Group (years) & $\begin{array}{l}\text { Clinical features* } \\
\text { Loose stools }\end{array}$ & Vomiting & Abdominal cramps & Fever \\
\hline \multirow{5}{*}{ Male } & $0-10$ & 04 & 01 & 02 & 01 \\
\cline { 2 - 6 } & $11-20$ & 10 & 03 & 02 & 02 \\
\cline { 2 - 6 } & $21-30$ & 13 & 05 & 03 & 02 \\
& $31-40$ & 07 & 02 & 01 & 01 \\
& $41-50$ & 01 & 0 & 0 & 0 \\
\cline { 2 - 6 } & $\geq 51$ & 03 & 01 & 0 & 0 \\
\hline \multirow{5}{*}{ Female } & $0-10$ & 04 & 0 & 01 & 0 \\
\cline { 2 - 6 } & $11-20$ & 03 & 01 & 0 & 0 \\
& $21-30$ & 02 & 0 & 0 & 0 \\
\cline { 2 - 6 } & $31-40$ & 05 & 01 & 02 & 0 \\
& $41-50$ & 04 & 02 & 0 & 01 \\
\hline
\end{tabular}

* Multiple responses.

Table 4: Resistance patterns of Vibrio cholerae isolates.

\begin{tabular}{|llll|}
\hline Drug & Resistant isolate (\%) & Drug & Resistant isolate (\%) \\
\hline Doxycycline & 32 & Cephalexin & 20 \\
\hline Ofloxacin & 25 & Amikacin & 15 \\
\hline Ampicillin & 65 & Gentamycin & 15 \\
\hline Tetracycline & 40 & Chloramphenicol & 58 \\
\hline
\end{tabular}

\section{DISCUSSION}

In this study males were more commonly suffered from cholera as compared to females, male: female ratio was 1.52:1 which was similar to N. C. Sharma et al, Ankur Joshi et al and Subarna Roy et al study. ${ }^{8-10}$ It was observed that both genders and all age group were affected by cholera. These findings are comparable with the findings of Chander $\mathbf{J}$ et al study. ${ }^{11}$ In the present study maximum affected population group was 21-30 years which was similar to study done by Abhijit Dutta et al and B. N. Mahanta et al. ${ }^{412}$ In the developing world where sustained transmission is possible, a single case or small outbreak can lead to a larger epidemic. ${ }^{13}$ It is known that cholera epidemics occur where there is admixture between drinking water and sewage due to breaches in the pipelines. It was in fact revealed after survey done in Miraj and Sangli that there existed this type of drinking water contamination in municipal water supply. Due to lack of support from local health authorities of Kolhapur district and Karnataka state source of water contamination couldn't found which the limitation of the present study was. In fact first few cases of outbreak was from Kolhapur so health education regarding safe drinking water, use of chlorine tablets, proper sanitation measures and personal hygiene couldn't be done and there was further cases of cholera outbreak in Miraj and Sangli. In the present study, cholera cases were seen in January and February which was unusual but similar to reports of Singh et al and Charles W. Hoge et al study. ${ }^{14,15}$ A similar outbreak emerged in the Sangli district of Maharashtra state during February and March 2005 . $^{13}$ Also cholera cases were seen in June and July months; these results are in agreement with other studies done in different parts of the country. ${ }^{11,16,17}$ In this study, not a single strain of Vibrio cholerae O139 was isolated. Mathur M. et al Anushka V Devnikar et al and Kulkarni $\mathrm{RD}$ et al did not isolate strains of $\mathrm{O} 139$ in their areas either. ${ }^{9,13,18}$ Although, oral rehydration solution is the mainstay of treatment, antimicrobial therapy is a useful adjuvant as it substantially reduces the duration and volume of diarrhoea; thereby lessening fluid requirements and shortening the duration of hospital stay. ${ }^{20}$ Among antibiotics tested, amikacin and gentamycin were most effective against $85 \%$ of isolates. Several studies also observed multidrug resistant cholera (Mishra et al, Neelam Taneja et al, Akond et al, Das et al, Jain et al, Ghosh \& Ramamurthy, Bhattacharya et al, Suchismita Dey et al. ${ }^{21-28}$ Tetracycline has been shown to be effective treatment for cholera, and is superior to furazolidone, cholamphenicol and sulfaguanidine in reducing cholera morbidity. Treatment with a single $300 \mathrm{mg}$ dose of doxycycline has shown to be equivalent to tetracycline treatment. Resistance to tetracycline and other antimicrobial agents among $\mathrm{V}$. cholerae has been demonstrated in both endemic and epidemic cholera settings. Resistance can be acquired through the accumulation of selected mutations over time, or the acquisition of genetic elements such as plasmids, introns, or conjugative elements, which confer rapid spread of resistance. A likely risk factor for antimicrobial resistance is widespread use of antibiotics, including mass 
distribution for prophylaxis in asymptomatic individuals ${ }^{[28]}$. However, additional studies are required to determine the role of these factors in the development of resistance among the $\mathrm{V}$. cholerae isolates in this region.

\section{CONCLUSION}

Provision of safe drinking water, improving sanitation and strengthening of disease surveillance especially in coordination with local health authorities across the border is necessary to avoid recurrences of cholera. The fast emergence of multidrug resistant $\mathrm{V}$. cholerae specifically to the drugs recommended by WHO for control of cholera is a cause for major concern. Additional studies are required to determine the role of these factors in the development of resistance among the V. cholera.

\section{ACKNOWLEDGEMENTS}

Authors duly acknowledge Dr. S. S. Rajderkar, Professor and HOD, Community Medicine Department, Government Medical College, Miraj for their support and giving permission for conducting the present study

Funding: No funding sources Conflict of interest: None declared

Ethical approval: The study was approved by the Institutional Ethics Committee

\section{REFERENCES}

1. WHO Cholera Fact sheet $\mathrm{N}^{0}$ 107. Cited 2016 May 1. Available at: http://www.who.int/mediacentre/ factsheets/fs107/en/.

2. Ghany MAE, Chander J, Mutreja A, Rashid M, HillCawthorne GA, et al. The population structure of Vibrio cholerae from the Chandigarh Region of Northern India. PLoS Negl Trop Dis. 2014;8(7):e2981.

3. Taneja N, Biswal M, Tarai B, Sharma M. Emergence of Vibrio cholerae O1 Biotype El Tor Serotype Inaba in North India. Jpn J Infect Dis. 2005;58:238-40.

4. Dutta A, Q Jawed, Mahanta BN, Mahanta TG, D Payeng, Rochan Sinha. Investigation of a cholera outbreak in a tea garden of Sivasagar district of Assam. Indian Journal of Community Medicine. 2013;38(4):240-3.

5. Old DC. Vibrio and related genera. In: Mackey and Mackie practical medical microbiology. Collee G, Duguid P, Fraser G, Marian P.14 ${ }^{\text {th }}$ ed. Delhi. Churchill Livingstone Publishers; 2007:425-46.

6. Bauer AW, Kirby WM, Sherris JC, Turck M. Antibiotic susceptibility testing by a standardized single disc method. Am J Clin Pathol. 1966;45:4936.

7. Snider DE Jr, Stroup DF. Defining research when it comes to public health. Public Health Rep. 1997;112:29-32.
8. Sharma NC, Mandal PK, Dhillon R, Jain M. Changing pattern of Vibrio cholerae O1, O139 in Delhi and its periphery (2003-2005). Indian J Med Res. 2007;125(5):633-40.

9. Joshi A, Kale S. Cholera like expression of Escherichia E coli: an outbreak investigation from Central India. Int $\mathrm{J}$ Med Public Health. 2013;3(3):151-4.

10. Roy S, Parande MV, Mantur BG, Bhat S, Shinde R, Parande AM, et al. Multidrug-resistant Vibrio cholerae $\mathrm{O} 1$ in Belgaum, South India. Journal of Medical Microbiology. 2012;61:1574-9.

11. Chander J, Kaistha N, Gupta V, Mehta M, Singla N, Deep A, Sarkar BL. Epidemiology and antibiograms of Vibrio cholerae isolates from a tertiary care hospital in Chandigarh, North India. Indian J Med Res. 2009;129:613-7.

12. Mahanta BN, Mahanta TG, Sinha R, Dutta A, Payeng DJ, Jawed MQ. Cholera outbreak in tea garden of Sivasagar district of Assam. J Acad Indus Res. 2013;1(8):493-6.

13. Kulkarni RD, Patil SA, Kulkarni VA, Ramteerthakar M, Kumbhar V, Shah SR, Joshi PA, Jahagirdhar VL. An outbreak of cholera in the Sangli District of Maharashtra. Indian $\mathrm{J}$ Med Microbiol. 2007;25:76-8.

14. Singh J, Khanna KK, Dhariwal AC, Bhattacharjee J, Singh M, Jain DC, et al. Unusual occurrence of cholera in Delhi during January 1994: epidemiological investigations. J Diarrhoeal Dis Res. 1996;14:107-9.

15. Hoge CW, Bodhidatta L, Echeverria P, Deesuwan M, Kitporka P. Epidemiologic study of Vibrio cholerae 01 and 0139 in Thailand: at the advancing edge of the $8^{\text {th }}$ Pandemic. Am $\mathrm{J}$ Epidemiol. 1996;143(3):263-8.

16. Sharma NC, Mandal PK, Dhillon R, Jain M. Changing profile of Vibrio cholerae O1, O139 in Delhi and its periphery (2003-2005). Indian J Med Res. 2007;125:633-40.

17. Nair GB, Ramamurthy $T$, Bhattacharya MK, Krishnan T, Ganguly S, Saha DR. Emerging trends in the etiology of enteric pathogens as evidenced from an active surveillance of hospitalized diarrhoeal patients in Kolkata. India. Gut Pathog. 2010;2(4).

18. Mathur M, De A, Saraswathi K, Varaiya A, Athalye S. Vibrionaceae from cases of acute diarrhoea and their antimicrobial sensitivity pattern: a five year prospective study. Indian $\mathbf{J}$ Med Microbiol. 2003;21(3):199-201.

19. Devnikar AV, Sonth SB, Baragundi MC, Solabannavar SS and Kulkarni RB. Characterization and Antibiogram of Vibrio cholerae isolates from a tertiary care hospital. Int J Biol Med Res. 2012;3(4):2352-4.

20. Nair GB. How much more research is required to prevent cholera? Indian J Med Res. 2007;125:612-4.

21. Mishra M, Mohammed F, Akulwar SL, Katkar VJ, Tankhiwale NS, Powar RM. Re-emergence of El 
Tor vibrio in outbreak of cholera in and around Nagpur. Indian J Med Res. 2004;120:478-80.

22. Taneja N, Rao P, Rao DSVR, Singh M, Sharma M. Enterotoxigenic Escherichia coli causing Cholerogenic Syndrome during an Interepidemic Period of Cholera in North India. Jpn J Infect Dis. 2006;59:245-8.

23. Akond MA, Alam S, Hasan SMR, Uddin SN, Shirin M. Antibiotic resistance of Vibrio cholerae from poultry sources of Dhaka, Bangladesh. Advan Biol Res. 2008;2:60-7.

24. Das S, Saha R, Kaur IR. Trend of antibiotic resistance of Vibrio cholerae strains from East Delhi. Indian J Med Res. 2008;127:478-82.

25. Jain M, Goel AK, Bhattacharya P, Ghatole M, Kamboj DV. Multidrug resistant Vibrio cholerae O1 El Tor carrying classical ctxB allele involved in a cholera outbreak in South Western India. Acta Trop. 2011;117:152-6.

26. Ghosh A, Ramamurthy T. Antimicrobials and cholera: are we stranded? Indian J Med Res. 2011;133:225-31.
27. Bhattacharya D, Sayi DS, Thamizhmani R, Bhattacharjee H, Bharadwaj AP, Roy A, et al. Emergence of multidrug-resistant Vibrio cholerae O1 Biotype El Tor in Port Blair, India. Am J Trop Med Hyg. 2012;86:1015-7.

28. Dey S, Parande MV, Parande AM, Lakkannavar SL, Rathore PK, Mantur BG, et al. Twin outbreak of cholera in rural North Karnataka, India. Indian J Med Res. 2014;140:420-6.

29. Centers for Disease Control and Prevention. Cholera- Vibrio Cholerae Infection. Recommendations for the Use of Antibiotics for the Treatment of Cholera. Cited 2016 May 1. Available at: http://www.cdc.gov/cholera/treatment/antibiotictreatment.html\#twentyone.

Cite this article as: Nandimath VA, Nandimath SA, Swamy CS, Ukrande AR. Epidemiological study of drug resistant cholera in and around Miraj, India. Int $\mathbf{J}$ Community Med Public Health 2016;3:2058-63. 